\title{
Surface Diffusion of Potassium Coadsorbed with CO on Ru(001): A Coverage Grating-Optical Second Harmonic Diffraction Study
}

\author{
I. M. Danziger, B. Hallac, and M. Asscher* \\ Department of Physical Chemistry and the Farkas Center for Light Induced Processes, The Hebrew University, \\ Jerusalem 91904, Israel
}

Received: February 16, 2004; In Final Form: July 6, 2004

\begin{abstract}
The effect of coadsorbed $\mathrm{CO}$ on potassium surface diffusion on $\mathrm{Ru}(001)$ has been studied using coverage grating-optical second harmonic diffraction method. The enhancement of the first-order diffraction peak at $0.06 \mathrm{ML}$ of $\mathrm{CO}$ coadsorption coverage demonstrates the very strong electronic interaction between these coadsorbates. At an initial potassium coverage of 1.0 ML, the activation energy for the diffusion of $\mathrm{K}$ increases from $2.7 \mathrm{kcal} / \mathrm{mol}$ on the clean ruthenium surface to $17.0 \mathrm{kcal} / \mathrm{mol}$ in the presence of $0.06 \mathrm{ML}$ CO. At 280 $\mathrm{K}$, the diffusion rate coefficient drops from $D=6.4 \times 10^{-10} \mathrm{~cm}^{2} / \mathrm{s}$ on clean ruthenium to $D=1.5 \times 10^{-14}$ $\mathrm{cm}^{2} / \mathrm{s}$ as a result of $\mathrm{CO}$ coadsorption. $\mathrm{CO}$ and $\mathrm{K}$ stabilize each other upon the formation of $\mathrm{K}_{y}-\mathrm{CO}_{x}$ surface complexes that increase the apparent activation energy for potassium diffusion, thereby slowing its diffusion rate.
\end{abstract}

\section{Introduction}

Surface diffusion has become a popular subject for research with the development of scanning-probe microscopy, such as STM and AFM. Studies of diffusion have primarily emphasized motion at the low-coverage regime and in the microscopic scale, that is, site-to-site hopping/diffusion, ${ }^{1-4}$ which has been demonstrated to be affected by complex adsorbate-surface and adsorbate-adsorbate interactions. ${ }^{5-8}$ For the purpose of monitoring macroscopic scale surface diffusion, laser-induced thermal desorption (LITD) techniques were introduced to form a periodic coverage modulation on a surface. Diffusion can then be monitored by employing optical diffraction, either second harmonic or linear. ${ }^{9-16}$ In these studies, the decay of the firstorder diffraction peak directly reflects the 1D diffusion process at a given surface temperature. When repeated at several crystal temperatures, the activation energy can be obtained via Arrhenius analysis. ${ }^{7}$

Several coadsorption systems have been studied using the LITD hole-refilling technique. ${ }^{17-21}$ Coadsorption attraction and site blocking often played an important role in determining the diffusion rates. The system of $\mathrm{CO}-\mathrm{K}$ has been the subject of numerous experimental and theoretical investigations on several metal substrates, ${ }^{21-30}$ concluding that coadsorbed potassium and $\mathrm{CO}$ tend to form stable surface complexes. The nature of those complexes has been discussed in the literature and has been found to be substrate specific. In the case of $\mathrm{Ru}(001)$, Weimer et al. claimed that there is more than one $\mathrm{K}_{y}-\mathrm{CO}_{x}$ complex, suggesting 1:1 and 2:3 x/y ratio complexes, ${ }^{27,28}$ whereas Madey et al. have suggested that potassium and $\mathrm{CO}$ make complexes of the type $\mathrm{K}_{y}(\mathrm{CO})_{2 y} .{ }^{30}$ The diffusion of this system on $\mathrm{Ru}(001)$ was investigated by Westre et al. by employing the hole-refilling method. The diffusion length in their study has been typically on the order of $\sim 100 \mu \mathrm{m}$. They found that potassium and CO form a stable surface compound with the stoichiometry of $\mathrm{K}-\mathrm{CO}$, namely, $y / x$ of $1: 1 .^{21}$ The LITD coverage grating-SHG diffraction technique has been demonstrated to enable the

\footnotetext{
* Corresponding author. E-mail: asscher@fh.huji.ac.il.
}

monitoring of $1 \mathrm{D}$ surface diffusion in the length scale of 5-10 $\mu \mathrm{m}$. This method was used to investigate the surface diffusion of potassium in the presence of $\mathrm{CO}$ on $\operatorname{Re}(001)$ by Zhao et al.

It was shown that the $\mathrm{CO}-\mathrm{K}$ attraction leads to a significant increase in the activation energy and the preexponential factor for potassium surface diffusion. ${ }^{25}$

In this work, we present results on the effects of coadsorbed $\mathrm{CO}$ on the diffusion of potassium at the high coverage range on $\mathrm{Ru}(001)$. We show that the amount of $\mathrm{CO}$ coadsorbed on the $\mathrm{K} / \mathrm{Ru}(001)$ surface controls the potassium surface diffusivity because of the formation of more than one type of $\mathrm{K}_{y}-\mathrm{CO}_{x}$ surface complex.

\section{Experimental Section}

The experiments reported here were conducted in a UHV chamber with a typical base pressure of $2 \times 10^{-10}$ Torr. The preparation of the $\mathrm{Ru}(001)$ crystal followed standard cleaning procedures. The surface temperature was determined by a $\mathrm{W} 26 \% \mathrm{Re}-\mathrm{W} 5 \% \mathrm{Re}$ thermocouple spot that was welded to the backside of the sample, with a linear heating rate of $1-20 \mathrm{~K} / \mathrm{s}$ and temperature stabilization algorithm with an accuracy of $\pm 0.5 \mathrm{~K}$.

Potassium was dosed onto the $\mathrm{Ru}(001)$ surface by passing current $(4.5-6.5$ A) through a commercial potassium source (SAES Getters) located approximately $10 \mathrm{~mm}$ from the sample. This was sufficient to produce a monolayer of potassium on the surface in $3 \mathrm{~min}$ of evaporation time. Reproducible potassium coverages were obtained by dosing potassium to coverage of more than a monolayer, in situ monitored by optical second harmonic generation (SHG) and then heating the surface to a known temperature to produce the desired coverage. TPD results have shown that this coverage-determination procedure results in more reproducible values than by simply controlling potassium dosing time and current. ${ }^{16}$ A full monolayer (ML) of potassium is defined as that just after the disappearance of the multilayer TPD peak at $335 \mathrm{~K}$ (Figure 1), where the potassium 


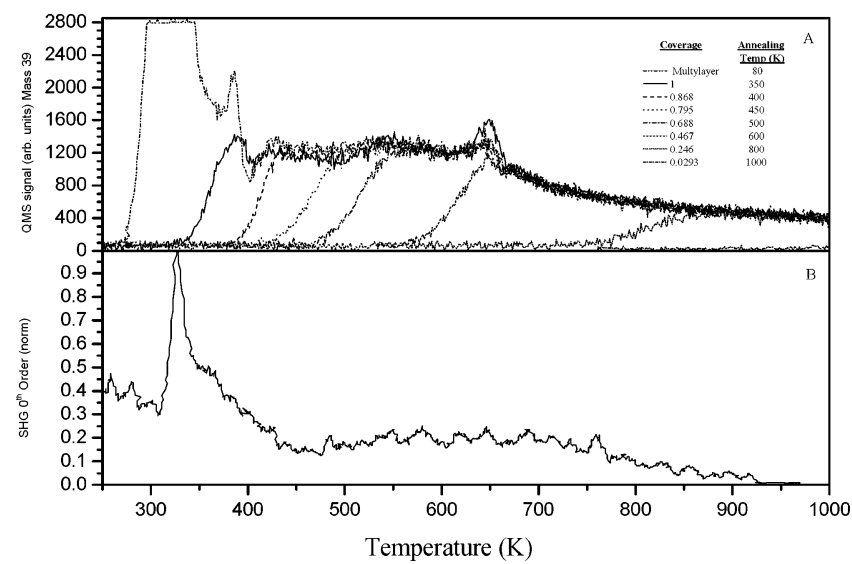

Figure 1. (a) TPD spectra of potassium from clean $\mathrm{Ru}(001)$ surface (b) SHG-TPD spectra of potassium from clean $\mathrm{Ru}(001)$ surface.

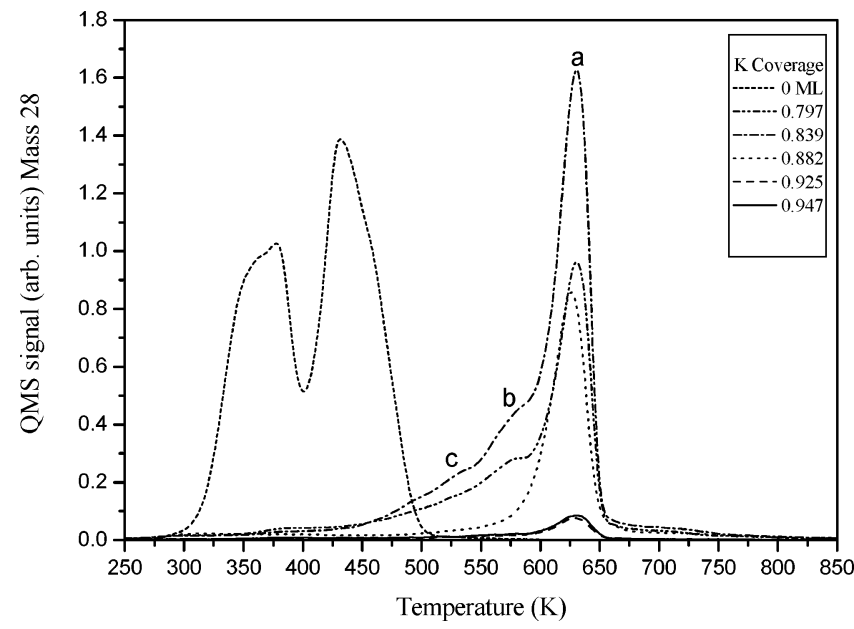

Figure 2. TPD spectra of $\mathrm{CO}$ from clean and $\mathrm{K}$ precovered $\mathrm{Ru}(001)$, as indicated.

SHG signal intensity is just over its maximum. This coverage corresponds to a ratio $\mathrm{K} / \mathrm{Ru}=0.33$, as it does on most hexagonal surfaces. ${ }^{22}$

$\mathrm{CO}$ was then dosed onto each of the potassium precovered surfaces. $\mathrm{CO}$ sticking on $\mathrm{K} / \mathrm{Ru}(001)$ has been determined by TPD analysis. Its coverage was measured by integrating the $\mathrm{CO}$ TPD spectra (Figure 2) and normalizing it to the TPD area that corresponded to a saturation coverage of $\mathrm{CO}$ on clean $\mathrm{Ru}(001)$. On the basis of the above TPD analysis, one can calculate the coverage profile of $\mathrm{CO}$ on the modulated potassium coverage prepared by the LITD-grating formation (Figure 3).

The optical setup used for this work has been based on a Nd:YAG laser (Quantel YG-585) at a fundamental wavelength of $\lambda=1.064 \mu \mathrm{m}$, repetition rate of $10 \mathrm{~Hz}$, and pulse duration of $10 \mathrm{~ns}$. The laser was used for both grating formation and SHG diffraction. In these experiments, a beam splitter forms two beams of equal intensities that strike the potassium-covered $\mathrm{Ru}(001)$ surface at incident angles of $\phi= \pm 5^{\circ}$ normal to the surface. The resulting grating period, given by $d=\lambda / 2 \sin \phi$, is, therefore, $6.1 \mu \mathrm{m}$. These beams spatially overlapped at the center of the sample, having a spot size of $0.4 \mathrm{~cm}^{2}$. The maximum effective laser intensity from the desorption laser actually absorbed by the ruthenium sample per pulse (both beams) was $10 \mathrm{MW} / \mathrm{cm}^{2}$. A spatial intensity modulation is formed under these conditions due to interference between the two beams. A fraction of the fundamental laser intensity was separated out by using a reflecting glass. This fraction was used as the SHG probe laser that was operated at an incident angle of $43^{\circ}$ normal

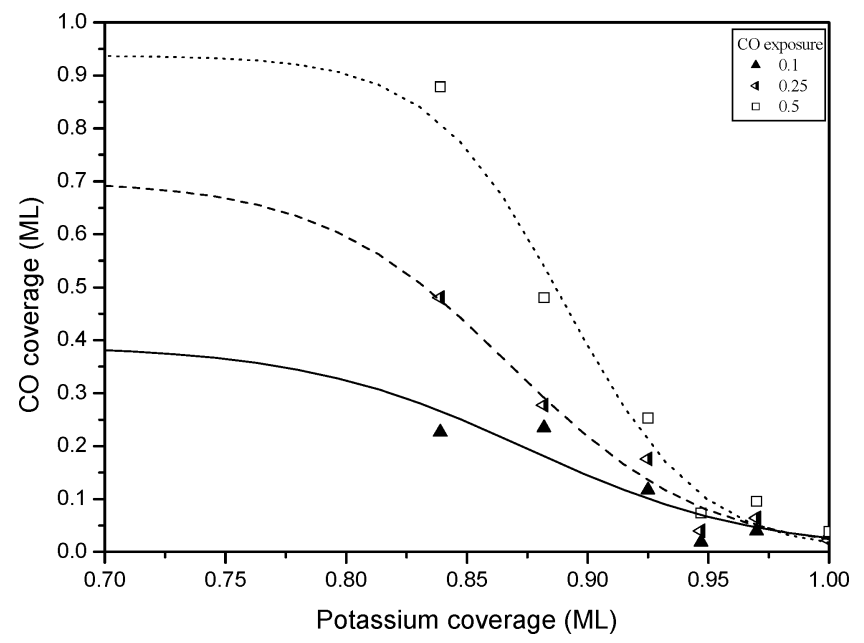

Figure 3. CO uptake (ML) vs K coverage for various $\mathrm{CO}$ exposures.

to the surface having a spot size smaller than that of the desorbing laser. The absorbed fundamental laser intensity of the probe beam was at most $3.2 \mathrm{MW} / \mathrm{cm}^{2}$, which corresponds to a maximum transient (20 ns) change in the surface temperature of $100^{\circ}$. During the short laser pulse, it does not affect the decay rate of the first-order SHG diffraction peak that reflects changes over a few micrometer range. The diffracted SH firstorder decay provides a direct probe of the potassium surface diffusion by fitting it to the appropriate solution of the Fick's second law of diffusion, which determines the diffusion coefficient. $^{9-16,25}$

\section{Results}

3.1. Potassium Coverage Grating and CO Surface-Coverage Profile. A detailed knowledge of the coverage-dependent desorption kinetics should be at hand before the modulated potassium coverage can be calculated. An electrostatic model was used to describe the activation energy for the desorption of $\mathrm{K}$ from $\mathrm{Ru}(001)$ as a function of its coverage, based on previous studies on $\operatorname{Re}(001) .{ }^{16}$ For the sake of simplicity, however, the preexponential factor for desorption was kept constant at $10^{13} \mathrm{~s}^{-1}$. The absorbed laser power density should then be measured to calculate the modulated surface-temperature profile caused by the two interfering laser beams. ${ }^{9-16}$ Once the time-dependent surface-temperature profile has been evaluated, the potassium desorption during the laser pulse can be calculated, leading to a calculated surface-coverage modulation profile. ${ }^{31-33}$

After the potassium-coverage profile was formed, the surface was exposed to $\mathrm{CO}$ at a given dose. The corresponding and complementary $\mathrm{CO}$-coverage profiles were obtained from the total $\mathrm{CO}$ uptake as a function of initial potassium coverage (Figure 4). The surface-coverage profile of the modulated $\mathrm{K}$ and $\mathrm{CO}$ along the surface (in micrometers), for initial potassium coverage of $1 \mathrm{ML}$, has been determined. The LITD absorbed laser power density was $10 \mathrm{MW} / \mathrm{cm}^{2}$ (75\% reflectivity of the laser beam at the fundamental wavelength of the Nd:YAG used here at $1064 \mathrm{~nm}$ ), and the actual potassium coverage within the grating troughs was $0.9 \pm 0.2 \mathrm{ML}$. The laser power used here ensures that the potassium-coverage modulation is shallow. This modulation is enough to generate the corresponding COcoverage modulation (Figure 3).

The average coverage is defined as the mean coverage along the entire grating length; therefore, we had to integrate the full grating period according to the results obtained from the LITD simulations. Because the most important density of the $\mathrm{CO}$ 


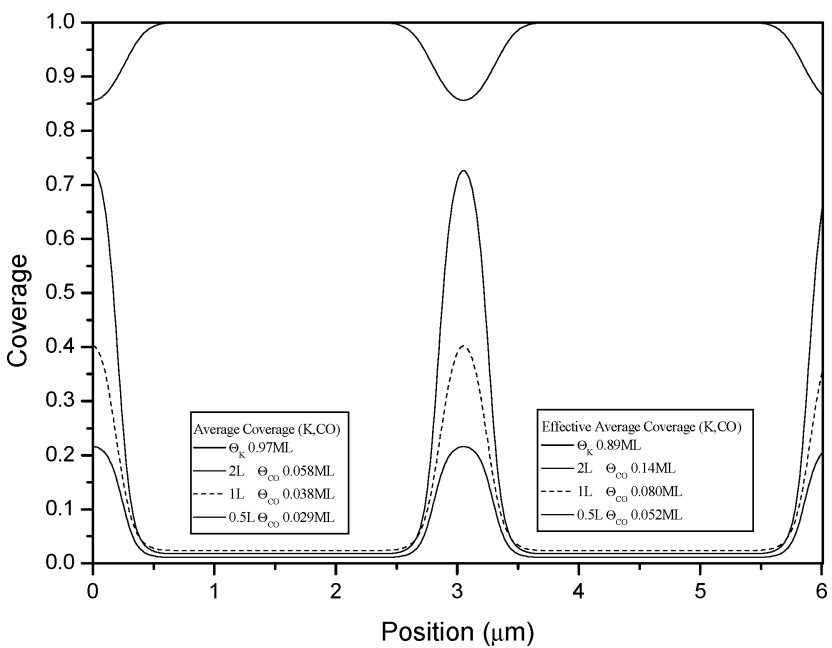

Figure 4. Potassium and $\mathrm{CO}$ lateral coverage profiles as obtained from LITD simulations, see text. The initial potassium coverage was 1.0 $\mathrm{ML}$, and the different $\mathrm{CO}$ coverage profiles are obtained at the indicated $\mathrm{CO}$ exposures.

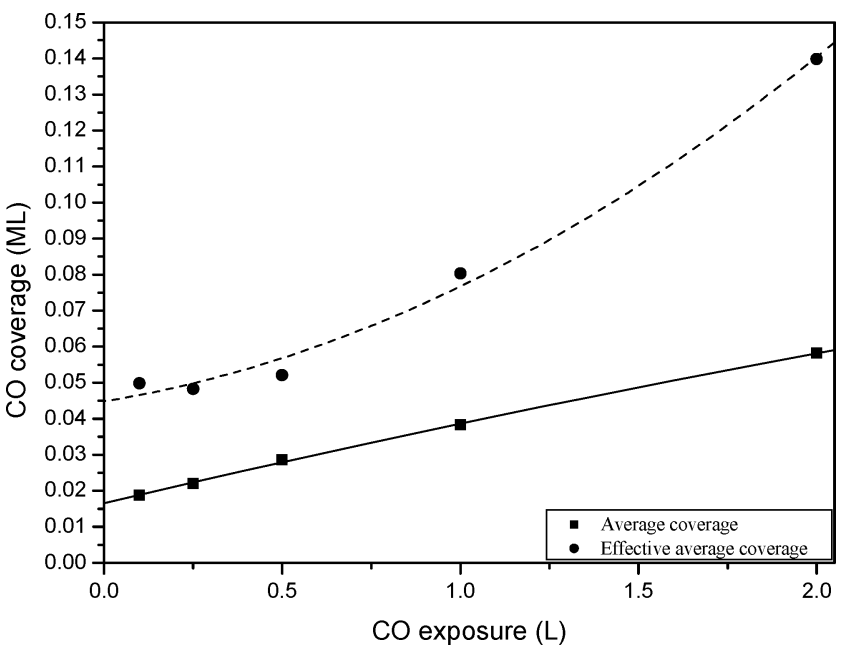

Figure 5. CO effective and average coverage (for definition see text) vs $\mathrm{CO}$ exposure for various potassium coverages. The average and within grating-trough (effective average) coverages are indicated in the figure.

molecules is inside the grating troughs, we have introduced another coverage definition, effective average coverage, which is obtained by integrating only the $\mathrm{CO}$ coverage inside the grating troughs. Figure 5 shows the $\mathrm{CO}$ effective average coverage as a function of $\mathrm{CO}$ exposure. The relatively shallow potassium modulation minimizes the potassium-coverage effect on the diffusion rate.

3.2. Effects of Coadsorbed CO on Potassium Surface Diffusion. The surface diffusion of potassium on $\mathrm{Ru}(001)$ in the presence of $\mathrm{CO}$ has been examined as a function of the $\mathrm{CO}$ exposure. Shown in Figure 6 are the decay curves of the firstorder $\mathrm{SH}$ diffraction peak with time at different surface temperatures for initial potassium surface coverage of 1.0 ML followed by $0.5 \mathrm{~L}$ of $\mathrm{CO}$ exposure. Ideally, if the diffusion coefficient is independent of surface coverage and the SH signal is directly proportional to the coverage squared, ${ }^{9}$ then the decay of the diffracted SH signal should be a single exponential. This is not expected to be the case in the presence of coadsorbed $\mathrm{CO}$ because this molecule quenches the $\mathrm{SH}$ response of the $\mathrm{K}$ adsorbate. Even if the above conditions do not strictly hold, the decay of the SH signal can be very close to an exponential as long as the coverage-modulation depth (determined by the

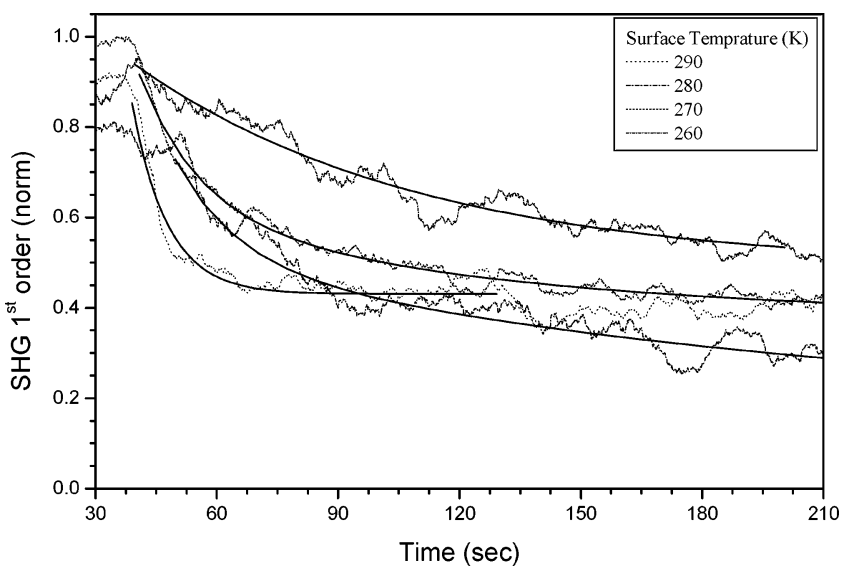

Figure 6. First-order SHG diffraction signal as a function of time during the diffusion of potassium at the indicated surface temperatures. The signal has been normalized to the same zero-time signal in each case. The initial potassium coverage was $1.0 \mathrm{ML}$, and the LITD laser power density was $10 \mathrm{MW} / \mathrm{cm}^{2}$. The solid lines through the data points are obtained from double exponential fits.

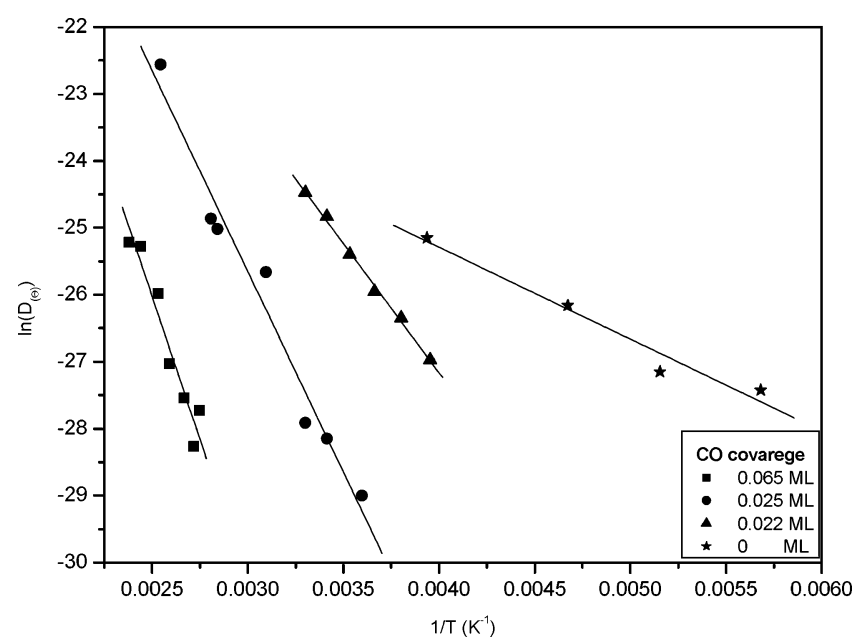

Figure 7. Arrhenius plots of the diffusion data in Figure 6. Here, the initial potassium coverage was $1.0 \mathrm{ML}$, and the $\mathrm{CO}$ average coverages are indicated in the figure.

LITD laser intensity) is shallow. The decay curves (Figure 6) are clearly nonexponential. To obtain diffusion coefficients from Figure 6, we fitted each of the decay curves with a double exponential. The diffusion coefficients were then calculated only from the "fast" exponential component. The validity of this assumption has been examined and discussed in the case of potassium diffusion on $\operatorname{Re}(001)$, both pure and coadsorbed with CO. ${ }^{16,25}$ The slow component of the first-order decay at longer times is believed to originate from background $\mathrm{CO}$ accumulation, resulting in a gradual increase in activation energy for diffusion, as will be discussed below. The Arrhenius plots shown in Figure 7 are based on diffusion coefficients calculated from the data in Figure 6. The activation energy for diffusion and the preexponential factor, as a function of $\mathrm{CO}$ coverage, were calculated from the Arrhenius plots in Figure 7.

\section{Discussion}

4.1. CO-K Interactions. Studies of $\mathrm{CO}$ and $\mathrm{K}$ coadsorption over transition metals have shown that the initial sticking coefficient of $\mathrm{CO}$ on potassium-covered metal surfaces slightly increases or remains approximately constant for potassium coverage up to approximately $0.7 \mathrm{ML} .{ }^{34}$ At higher K coverage, there is a gradual decrease in the sticking probability. In the 


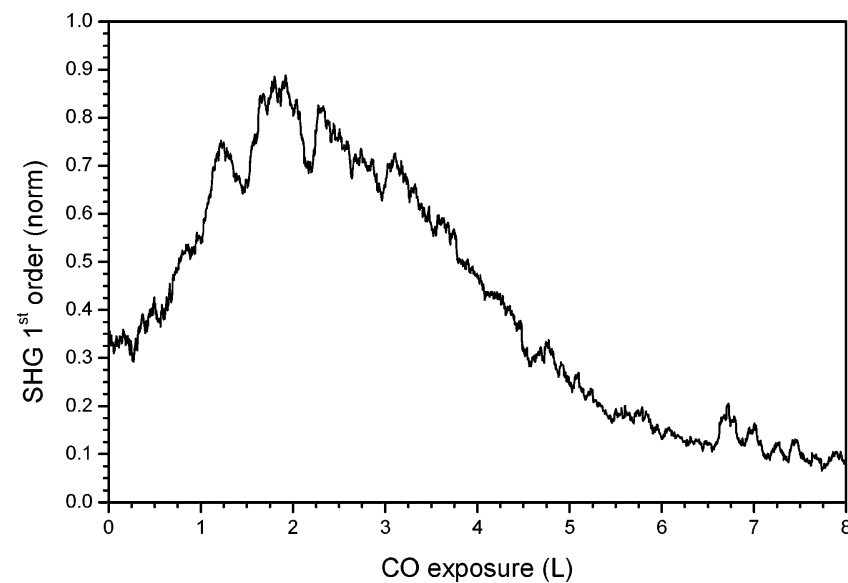

Figure 8. Influence of $\mathrm{CO}$ exposure on the first-order SHG signal from potassium coverage grating on $\mathrm{Ru}(001)$ at $95 \mathrm{~K}$.

case of potassium on $\mathrm{Ru}(001)$, the sticking of $\mathrm{CO}$ is practically constant up to potassium coverage of $0.85 \mathrm{ML}$, and then it gradually decreases with minimum sticking probability at $1 \mathrm{ML}$ (Figure 3). The mechanism of $\mathrm{CO}$ adsorption on alkali-metalcovered surfaces is complex. At the low-coverage regime, the adsorption of $\mathrm{CO}$ follows a precursor mechanism. ${ }^{35}$ At higher coverages, there is a conversion from ionic to neutral species as potassium coverage increases. ${ }^{36,37}$ This, together with the simple site-blocking effect, results in a reduced sticking coefficient. ${ }^{2}$. As shown in Figure 4, CO sticking and, therefore, its coverage changes along the surface, is inversely proportional to the potassium-coverage modulation. It is likely, therefore, that on top of occupied metallic potassium sites, $\mathrm{CO}$ molecules practically do not stick. Potassium thermal desorption from clean $\mathrm{Ru}(001)$ has been studied in detail using TPD, work function, and SHG methods, ${ }^{38}$ revealing a rather similar behavior to that of potassium on other transition metals, for example, $\operatorname{Re}(001){ }^{31}$

TPD and surface diffusion results of $\mathrm{CO}$ and $\mathrm{K}$ coadsorbed on $\mathrm{Ru}(001)$ show a mutual stabilization between $\mathrm{CO}$ and $\mathrm{K}$ as was reported on $\mathrm{Mo}(110)^{26}$ and $\mathrm{Ni}(110) .{ }^{39}$ The desorption temperature rises from 450 (clean $\mathrm{CO}$ ) to $630 \mathrm{~K}$ in the presence of $\mathrm{K}$. As expected, the desorption peak intensity diminishes as the amount of $\mathrm{K}$ on the surface increases. At $1 \mathrm{ML}$ of potassium, there is only one desorption peak at $630 \mathrm{~K}$, whereas at potassium coverage of $0.8 \mathrm{ML}$, there are at least three desorption peaks at temperatures lower than $630 \mathrm{~K}$. The stabilization is explained by the attraction between the two adsorbates and a $\pi^{*}$ complex formation that has better electronic interactions with the surface. $^{30}$ The dominant interaction between $\mathrm{CO}$ and $\mathrm{K}$ is strongly attractive, rather short range, and has more than a single possible structure..$^{27,30}$ Such a complex would also lead to a coincident $\mathrm{K}$ and $\mathrm{CO}$ desorption spectra because of their mutual stabilization, which will have a strong effect on the diffusion of potassium on the surface. ${ }^{31}$

The optical second harmonic (SH) response of a solid surface is typically sensitive to changes in adsorbate-surface electronic structure via the second-order susceptibility of the substrate. ${ }^{40-42}$ On a clean substrate, the strong $\mathrm{SH}$ response of the potassiumcovered surface is due to the particularly large second-order susceptibility of the alkali-metal complex at the fundamental laser wavelength of $1.064 \mu \mathrm{m}$. Electron transfer between $\mathrm{K}-4 \mathrm{~S}$ to the antibonding $\mathrm{CO}-2 \pi^{*}$ is therefore expected to influence significantly the $\mathrm{SH}$ response of the $\mathrm{K}$-metal complex (e.g., Figure 8).

The first-order SHG response of $\mathrm{K}$ on $\mathrm{Ru}(001)$ increases to a maximum at a $\mathrm{CO}$ exposure of $2 \mathrm{~L}$, for average potassium coverage of $0.9 \mathrm{ML}$, followed by quenching at higher $\mathrm{CO}$

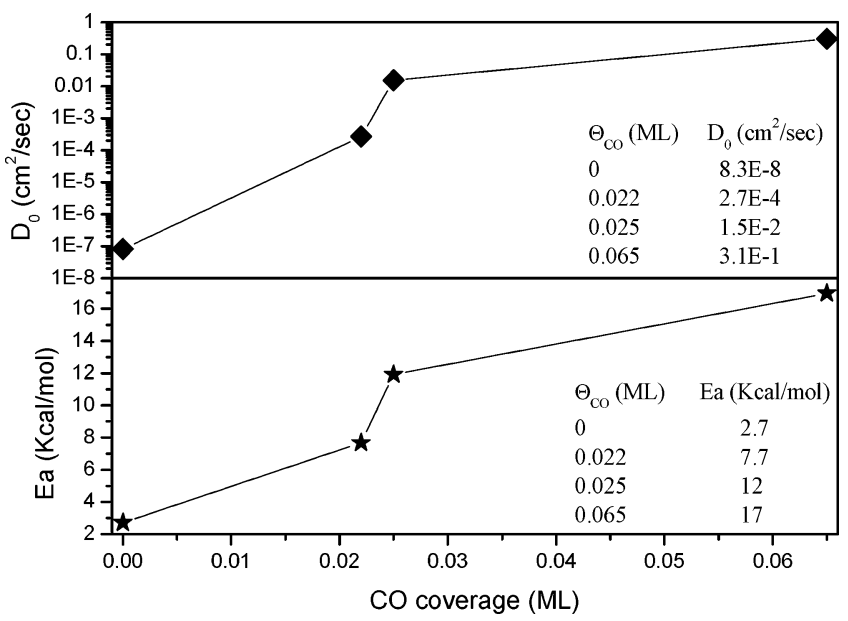

Figure 9. (a) Preexponentials for potassium surface diffusion $D_{0}$ as a function of $\mathrm{CO}$ average coverage for an initial potassium coverage of 1.0 ML (b) Activation energies for potassium diffusion as a function of $\mathrm{CO}$ average coverage at initial potassium coverage of $1.0 \mathrm{ML}$.

exposures (Figure 8). Similar results were reported previously on top of $\operatorname{Re}(001)$; however, smaller enhancement was found at the low CO coverage. ${ }^{25}$ This is in contrast to the case of $\mathrm{NH}_{3}$ on $\mathrm{Re}(001)$, where a minute amount of $\mathrm{CO}$ very effectively quenches the SHG signal. ${ }^{43}$

Unlike the zero-order diffraction peak, higher-order peaks are determined by the Fourier components of the periodic-coverage profile formed by the interference of the LITD-grating formation laser pulse. ${ }^{9}$ The intensity ratio of the first-order signal to the zero-order diffraction peak should be dictated by the coverage modulation profile. Simulations of the dependence of the higherorder diffraction peak intensities on the modulation profile suggest that the intensity ratio of the first-order $\mathrm{SH}$ diffraction peak to the zero-order diffraction peak should increase as the coverage modulation profile becomes closer to a square wave in shape. ${ }^{32}$ The results shown in Figure 8 suggest that adsorbed $\mathrm{CO}$ reshapes the potassium-coverage profile on $\mathrm{Ru}(001)$ from the point of view of the $\mathrm{SH}$ response. The initial $\mathrm{CO}$ adsorbates (low exposures) preferentially stick to the area of lowest $\mathrm{K}$ coverages. The interaction at the bottom of the potassium troughs between $\mathrm{CO}$ and $\mathrm{K}$ are stronger, and local SH quenching is more efficient. This leads to the effective reshaping of the K-coverage modulation, thus enhancing the first-order diffraction peak, which significantly increases the magnitude of the ratio of first-order to zero-order diffraction intensity. ${ }^{32} \mathrm{~A}$ similar behavior was predicted to be possible during diffusion, if the lateral interactions among the coadsorbates are strongly repulsive. ${ }^{33}$

4.2. Effects of Coadsorbed CO on Potassium Surface Diffusion. The presence of low coverage of coadsorbed CO can significantly increase the barrier for potassium surface mobility. Both the activation energy and the preexponential factor strongly increase as larger amount of $\mathrm{CO}$ molecules are coadsorbed on the potassium grating (Figure 9a and b). For potassium initial coverage of $1.0 \mathrm{ML}$, the effective average $\mathrm{CO}$ coverage of approximately $0.07 \mathrm{ML}$ leads to an increase in the activation energy for surface diffusion of potassium on $\mathrm{Ru}(001)$ from $2.7 \mathrm{kcal} / \mathrm{mol}$ on the clean metal to $17.0 \mathrm{kcal} / \mathrm{mol}$ and the preexponential factor increases from $8.3 \times 10^{-8}$ to $3.1 \times 10^{-1}$ $\mathrm{cm}^{2} / \mathrm{s}$, respectively. The fact that the activation energy and the preexponential factor increase simultaneously is a manifestation of the well-known compensation effect, which was observed in low potassium coverage coadsorbed with $\mathrm{CO}$ and also in pure potassium diffusion on $\operatorname{Re}(001) .{ }^{16,21,38}$ 


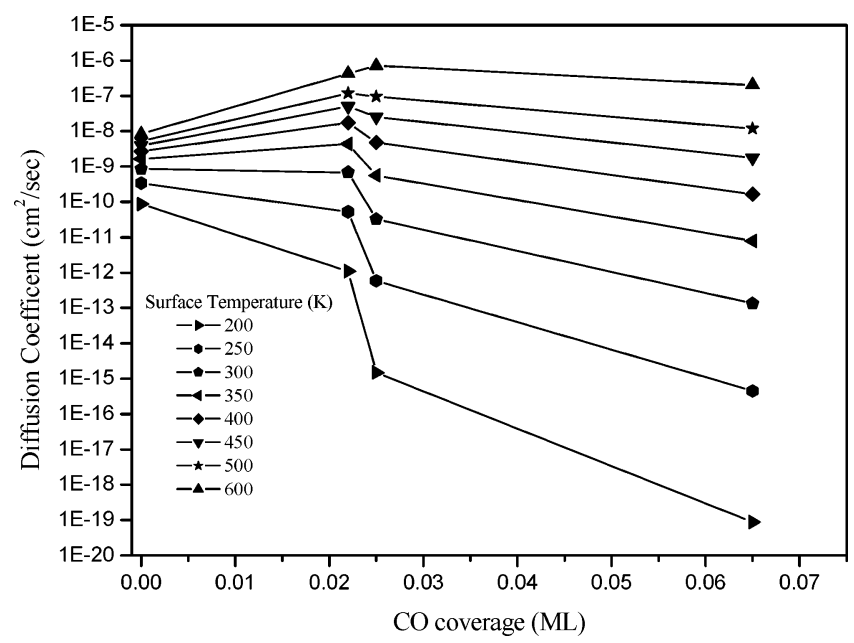

Figure 10. Potassium diffusion coefficient as function of $\mathrm{CO}$ average coverage at the indicated temperatures.

The diffusion coefficient is typically expressed in an Arrhenius form, $D=D_{0} \exp \left(-E_{\text {diff }} / R T\right) \mathrm{cm}^{2} / \mathrm{s}$, where $E_{\text {diff }}$ is the activation energy for diffusion and $D_{0}$ is the preexponential factor. From the numbers in Figure 9, one can derive the diffusion coefficient (Figure 10). The diffusion coefficient varies with temperature as follows: Below $300 \mathrm{~K}$, it decreases as the $\mathrm{CO}$ coverage increases, whereas at higher temperatures, the diffusion coefficient goes through a maximum at effective $\mathrm{CO}$ coverage of $0.025 \mathrm{ML}$. This maximum suggests that $x$ in the $\mathrm{K}_{y}-\mathrm{CO}_{x}$ complex changes with temperature. The value of $x$ gradually decreases with increasing temperature until the complex breaks down, and then the potassium freely migrates on the surface.

The diffusion coefficient of clean potassium at an initial coverage of $1 \mathrm{ML}$ on $\operatorname{Re}(001)$ was reported before ${ }^{16}$ to be $(2.3$ $\pm 0.8) \times 10^{-7} \mathrm{~cm}^{2} / \mathrm{s}$ at $250 \mathrm{~K}$. This is 3 orders of magnitude higher diffusivity than the results presented here for $\mathrm{Ru}(001)$. This large difference between the two metals may be due to the extremely high sensitivity to the presence of coadsorbed $\mathrm{CO}$ in the case of ruthenium at $1 \mathrm{ML}$ initial coverage of potassium, and minor background $\mathrm{CO}$ impurity also may have led to this large difference.

The effects of $\mathrm{CO}$ coadsorption on potassium diffusion is also much more pronounced in our study on $\mathrm{Ru}(001)$ compared with the effects reported in ref 21 on the same $\mathrm{Ru}(001)$ surface. The diffusion coefficient changes by 5 orders of magnitude (at $250 \mathrm{~K}$ ) when coadsorbing $\mathrm{CO}$ molecules on a grating of potassium on $\mathrm{Ru}(001)$. The authors in ref 21 report on a change of only 1 order of magnitude due to $\mathrm{CO}$ coadsorption on homogeneous distribution of lower coverage of potassium on the surface. In the case of coadsorption of $\mathrm{CO}$ on grating of potassium on $\operatorname{Re}(001)$, however, the diffusion coefficient changed only by 2 orders of magnitude. ${ }^{25}$

The different values for $D$ obtained by the hole-refilling technique ${ }^{17-21}$ and the coverage grating method may be explained mainly as a result of the higher potassium coverage used in this study, where site blocking is expected to dominate. In addition, the fact that the surface may be somewhat damaged during the hole-refilling experiment due to the high laser power needed for surface heating in order to desorb low potassium coverage needs to be considered. Furthermore, the diffusion length in the hole-refilling experiment is about 100-200 $\mu \mathrm{m}$, resulting in averaging of the diffusion coefficient over many inhomogeneous sites such as steps and other surface defects. Other supporting evidence for the small diffusion coefficient

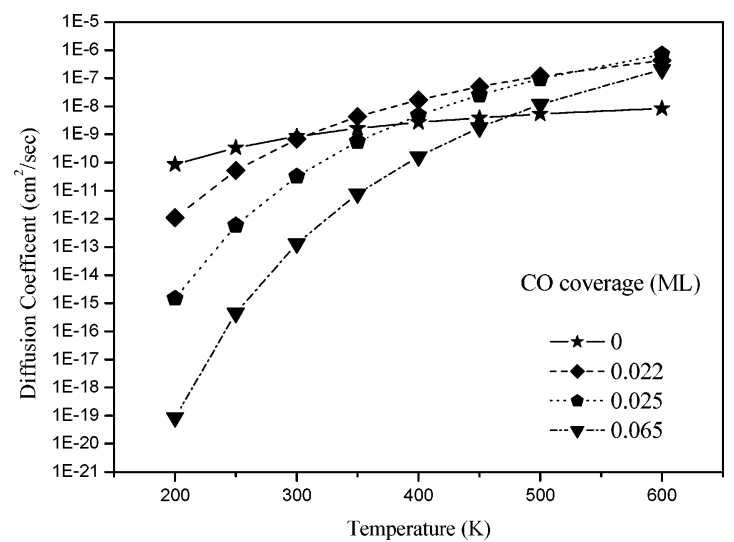

Figure 11. Potassium diffusion coefficient as function of temperature at the indicated $\mathrm{CO}$ coverages.

and barrier for diffusion of potassium on clean $\mathrm{Ru}(001)$ comes from a comparison of our results with those reported by Ellis et al. of sodium on $\mathrm{Cu}(001) .44,45$ They reported barrier for diffusion of $51 \mathrm{meV}$, that is, $2 \mathrm{kcal} / \mathrm{mol}$ for isolated sodium atoms on $\mathrm{Cu}(001)$. Similar results were obtained on other metallic surfaces. ${ }^{45-49}$

The effect of site-blocking on the surface diffusion of potassium atoms is indicated by the increase of activation energy and by the 6 orders of magnitude increase in the preexponential factor obtained by increasing the CO coverage on 1.0 ML of potassium (Figure 9). In ref 21, Westre at. al. have concluded that potassium and $\mathrm{CO}$ interact to form a complex having a 1:1 ratio between $\mathrm{K}$ and $\mathrm{CO}$ that is the most stable, and thus, the one that is actually formed on the surface. This complex leads to the diffusion of both $\mathrm{K}$ and $\mathrm{CO}$ to slow by a simple siteblocking effect. Earlier spectroscopic studies revealed the presence of other surface compounds, $\mathrm{K}_{y}-\mathrm{CO}_{x}(1 \leq y \leq 2$ and $1 \leq x \leq 3$ ) and not limited to the 1:1 ratio. Such compounds are the result of strong attractive interactions in the short range. ${ }^{27,30} \mathrm{In}$ all of these examples, the complexes become a physical block for potassium atoms to migrate thermally on the surface, whereas the complex does not migrate by itself. It is, therefore, reasonable to expect that the site blocking effect will increase as the $x / y$ ratio increases.

In this case, the inhomogeneous grating system gives us a unique insight into the nature of $\mathrm{K}-\mathrm{CO}$ interactions on metals. As discussed before, the coverage grating forms areas where the potassium coverage is $1 \mathrm{ML}$ and areas where the coverage is only $0.85 \mathrm{ML}$. The CO TPD uptake measurements reveal that, although on the $1 \mathrm{ML}$ potassium coverage segments $\mathrm{CO}$ practically does not stick, inside the troughs, the CO density is high enough to form strong interactions with the potassium atoms.

The diffusion coefficient varies as a function of $\mathrm{CO}$ coverage in those different domains: (a) Effective $\mathrm{CO}$ coverage (the local $\mathrm{CO}$ coverage within the trough) in the range of 0 to $0.048 \mathrm{ML}$, (b) 0.048 to $0.052 \mathrm{ML}$, and (c) 0.052to $0.14 \mathrm{ML}$. The examination of the diffusion coefficient as a function of temperature reveals that the calculated temperature effect between 200 and $600 \mathrm{~K}$ is more pronounced at the higher $\mathrm{CO}$ exposure, where the diffusion coefficient varies by 12 orders of magnitude, whereas for clean potassium, the change is limited to 2 orders of magnitude (Figure 11). This is an indication that, at the higher $\mathrm{CO}$ coverage, high activation energies for diffusion, determined experimentally, are due to the formation of $\mathrm{K}_{y}$ $\mathrm{CO}_{x}$ complexes with gradual increase in the $x / y$ ratio as the $\mathrm{CO}$ coverage increases. 
As the ratio of $x / y$ increases, larger surface compounds are formed, therefore, site blocking becomes more effective. Entropy considerations affecting the preexponential factor seem to influence the Arrhenius rate constant for diffusion in the same way as the growing activation energy for diffusion. This may explain the 12 orders of magnitude difference observed in the diffusion coefficient at the highest $\mathrm{CO}$ coverage with the largest $x / y$ ratio.

\section{Conclusions}

The mutual interaction and surface diffusion of potassium coadsorbed with $\mathrm{CO}$ in a template-coverage grating has been studied on $\mathrm{Ru}(001)$. Surface diffusion of potassium has been investigated in the presence of $\mathrm{CO}$ coadsorbate by using the coverage grating-optical second harmonic diffraction method. Effective $\mathrm{CO}$ coverage at the grating troughs has been calculated on the basis of the independently measured sticking of $\mathrm{CO}$ on the potassium-covered surface. Significant changes in the firstorder SHG diffraction peak intensities due to $\mathrm{CO}$ coadsorption emphasizes the complexity of this coadsorption system because the attractive interactions between $\mathrm{K}$ and $\mathrm{CO}$ affect the $\mathrm{SH}$ response and the optical-diffraction intensities.

The activation energy for diffusion and the preexponential factor significantly increase with $\mathrm{CO}$ coverage. At a potassium initial coverage of $1.0 \mathrm{ML}$ and an effective $\mathrm{CO}$ coverage of approximately $0.07 \mathrm{ML}$, the activation energy for potassium diffusion on $\mathrm{Ru}(001)$ increased from 2.7 to $17.0 \mathrm{kcal} / \mathrm{mol}$, and the preexponential factor increases from $8.3 \times 10^{-8}$ to $3.1 \times$ $10^{-1} \mathrm{~cm}^{2} / \mathrm{s}$. TPD measurements indicate that strong attractive interactions exist between $\mathrm{CO}$ and $\mathrm{K}$ on $\mathrm{Ru}(001)$. Coadsorbed $\mathrm{CO}$ and $\mathrm{K}$ are likely to stabilize each other through the formation of $\mathrm{K}_{y}-\mathrm{CO}_{x}$ surface complexes, the composition of which changes in nature as the local $\mathrm{CO}$ coverage conditions change. We conclude that these surface complexes act as site blockers to impede the surface diffusion of potassium, resulting in the most significant changes in both the activation energy and the preexponential factor as the sizes of these surface compounds increase with $\mathrm{CO}$ coverage. The diffusion coefficient $D(\vartheta)$ has been calculated to increase by 12 orders of magnitude in the case of the maximum $\mathrm{CO}$ to $\mathrm{K}$ ratio, as the temperature increases from 200 to $600 \mathrm{~K}$, whereas only 2 orders of magnitude increase are found for the clean potassium, in the same temperature range.

Acknowledgment. This work has been partially supported by the Israel Science Foundation and the U.S.-Israel Binational Science Foundation. The Farkas Research Center for Light Induced Processes is supported by the Minerva Gesellschaft für die Forschung, GmbH, München.

\section{References and Notes}

(1) Tsong, T. T. Mater. Sci. Eng., A 2003, 353, 1

(2) Rosei, F.; Rosei, R. Surf. Sci. 2002, 500, 395.

(3) Ala-Nissila, T.; Ferrando, R.; Ying, S. C. Adv. Phys. 2002, 513, 949.

(4) Barth, J. V. Surf. Sci. Rep. 2000, 40, 75

(5) Stolt, E.; Stolt, K. J. Annu. Rev. Phys. Chem. 1980, 31, 603.

(6) Gomer, R. Rep. Prog. Phys. 1990, 53, 917.

(7) Tringides, M. C. J. Chem. Phys. 1990, 92, 2077.

(8) Mašín, M.; Vattulainen, I.; Ala-Nissila, T.; Chvoj, C. Surf. Sci. Lett. 2003, 529, L256. (883.

(9) Zhu, X. D.; Raising, Th.; Shen, Y. R. Phys. Rev. Lett. 1988, 61,

(10) Reider, G. A.; Höfer, U.; Heinz, T. F. Phys. Rev Lett. 1991, 66 1994.

(11) Xiao, X. D.; Zhu, X. D.; Daum, W.; Shen, Y. R. Phys. Rev. Lett. 1991, 66, 2354

(12) Zhu, X. D.; Lee, A.; Wong, A.; Linke, U. Phys. Rev. Lett. 1992 $68,1862$.

(13) Zhu, X. D. Mod. Phys. Lett. B 1992, 6, 1217

(14) Asscher, M.; Rosenzweig, Z. Optical Second Harmonic Generation as a Real Time Probe of Gas-Surface Interactions. In Laser Spectroscopy and Photochemistry on Metal Surfaces Dai, H.-L., Ho, W., Eds., Advanced Series in Physical Chemistry World Scientific: Singapore, 1995; Vol. 5 , Chapter 4, Part 1.

(15) Rosenzweig, Z.; Farbman, I.; Asscher, M. J. Chem. Phys. 1993, 98,8277

(16) Zhao, W.; Verhoef, R. W.; Asscher, M. J. Chem. Phys. 1997, 107, 5554.

(17) Mak, H.; Koehler, B. G.; Brand, J. L.; George, S. M. J. Chem. Phys. 1987, 87, 2340

(18) Brown, E.; Sholl, D. S.; Skodje, R. T.; George, S. M. Chem. Phys. 1995, 201, 273 457

(19) Brand, J. L.; Deckert, A. A.; George, S. M. Surf. Sci. 1988, 194,

(20) Mak, C. H.; Deckert, A. A.; George, S. M. J. Chem. Phys. 1988 , 89,5242 .

(21) Westre, D.; Brown, D. E.; Kutzner, J.; George, S. M. J. Chem Phys. 1996, 104, 7313

(22) Bonzel, H. P. Surf. Sci. Rep. 1988, 8, 43

(23) Bonzel, H. P.; Pirug, G. in The Chemical Physics of Solid Surfaces: Coadsorption, Promoters and Poisons; King, D. A., Woodruff, D. P., Eds.; Elsevier Science: Amsterdam, 1993; Vol. 6.

(24) Physics and Chemistry of Alkali Metal Adsorption; Bonzel, H. P., Bradshaw, A. M., Ertl, G., Eds.; Material Science Monographs 57; Elsevier Science: Amsterdam, 1989.

(25) Zhao, W.; Asscher, M. Surf. Sci. 1999, 429, 1.

(26) Bugyi, L.; Solymosi, F. J. Phys. Chem. 2001, 105, 4337. (CO ond $\mathrm{K}$ on $\mathrm{Mo}$ ).

(27) Weimer, J.; Umbach, E.; Menzel, D. Surf. Sci. 1985, 155, 132

(28) Weimer, J.; Umbach, E.; Menzel, D. Surf. Sci. 1985, 159, 83.

(29) Crowell, J. E.; Garfunkel, E. L.; Somorjai, G. A. Surf. Sci. 1982, 121,303

(30) Madey, T. E.; Benndrof, C. Surf. Sc. 1985, 164, 602.

(31) Verhoef, R. W.; Zhao, W.; Asscher, M. J. Chem. Phys. 1997, 106 9353.

(32) Verhoef, R. W.; Asscher, M. Surf. Sci. 1997, 376, 389.

(33) Verhoef, R. W.; Asscher, M. Surf. Sci. 1997, 376, 395.

(34) Westre, D.; Brown, D. E.; Kutzner, J.; George, S. M. Surf. Sci. 1993, 294, 185

(35) Kisliuk, P. J. Phys. Chem. Solids 1957, 3, 95

(36) Verhoef, R. W.; Asscher, M. Surf. Sci. 1997, 391, 11.

(37) Hrbek, J.; Shek, M.-L.; Sham, T. K.; Xu, G.-Q. J. Chem. Phys. 1989, $91,5786$.

(38) Kerner, G.; Danziger, I. M.; Zhao, W.; Asscher, M. In Collective Diffusion on Surfaces: Correlaation Effects and Adatom Interaction; Tringides, M. C., Chvoj, Z.; Eds.; NATO Science Series 2, Mathematics, Physics and Chemistry, Vol. 29; Kluwer Academic: Dordrecht, The Netherlands, 2001.

(39) Whitman, L. J.; Ho, W. J. Chem. Phys. 1985, 83, 4808.

(40) Shen, Y.R. In The Structure of Surface Van Hove, M. A., Tong, S. Y., Eds.; Springer Series in Surface Science, Vol. 2; Springer: Berlin, 1985; p 77 and references therein.

(41) Tom, W. K.; Zhu, X. D.; Shen, Y. R.; Somorjai, G. A. Surf. Sci 1986, 167,167

(42) Heinz, T. F.; Tom, H. W. K.; Shen, Y. R. Phys. Rev. A 1983, 28 1883.

(43) Rosenzweig, Z.; Asscher, M.; Wittenzellner, C. Surf. Sci. Lett. 1990 240, L583.

(44) Ellis, J.; Toennies, J. P. Phys. Rev. Lett. 1993, 70, 2118.

(45) Ellis, J.; Graham, A. P.; Hofmann, F.; Toennies, J. P. Phys. Rev. B 2001, 63, 195408

(46) Joyner, R. W. In Advances in Catalysis; Frankenburg, W. G., Ed.; Academic Press: New York, 1952; Vol. 4.

(47) Solymosi, F.; Berko, A. Surf. Sci. 1988, 201, 361.

(48) Al-Sarraf, N.; Stuckless, J. T.; King, D. A. Nature 1991, 360, 243.

(49) Graham, A. P.; Toennies, J. P. Surf. Sci. 1999, 427-428, 1. 